В Е С Т Н К ПНИП У

2017

Машиностроение, материаловедение

T. 19, № 1

DOI: $10.15593 / 2224-9877 / 2017.1 .06$

УДК 669.018.298

\author{
А.Н. Юрченко, Д.О. Панов, Ю.Н. Симонов \\ Пермский национальный исследовательский \\ политехнический университет, Пермь, Россия
}

ИЗМЕНЕНИЕ МИКРОСТРУКТУРЫ

ЭКОНОМНОЛЕГИРОВАННОЙ СТАЛИ В ЗАВИСИМОСТИ

\author{
ОТ СКОРОСТИ НЕПРЕРЫВНОГО ОХЛАЖДЕНИЯ \\ И ТЕМПЕРАТУРЫ ИЗОТЕРМИЧЕСКОЙ ВЫДЕРЖКИ
}

На индукционном высокоскоростном закалочном дилатометре проведены различные режимы термической обработки сплава, содержащего 0,29 \% углерода, а также хром, марганец, кремний, молибден, ванадий. В результате анализа дилатометрических кривых построены термокинетическая и изотермическая диаграммы распада переохлажденного аустенита. В статье анализируется микроструктура экономнолегированной стали в зависимости от скорости непрерывного охлаждения с температуры аустенитизации и температуры изотермической выдержки. Дается сравнение микроструктуры сплава со значениями общей микротвердости при нагрузке 100 г на нетравленом микрошлифе. Подсчитана по дилатометрическим кривым доля различных структурных составляющих при непрерывном охлаждении и изотермической закалке. Определены критические точки сплава, которые необходимо знать для назначения более точной температуры нагрева под закалку для получения требуемых механических свойств. Выявлено, что в процессе трехчасовой изотермической выдержки бейнитное превращение полностью заканчивается, а оставшаяся доля аустенита при дальнейшем охлаждении или претерпевает мартенситное превращение, или остается неизменной. На основе проведенного исследования выдвинуты некоторые предположения о том, что для получения максимальной доли бейнитной фазы (или бескарбидного бейнита) следует применять изотермическую выдержку чуть ниже температуры начала мартенситного превращения, а для получения максимальных прочностных характеристик следует применять изотермическую выдержку максимально близко к температуре конца мартенситного превращения, так как твердость бейнита в этом случае максимальна и образуется наибольшее количество пакетного мартенсита. Особое внимание обращается на устойчивость остаточного аустенита. После непрерывного охлаждения и изотермической закалки доля аустенита является незначительной, что подтверждается снимками микроструктуры.

Ключевые слова: бейнит, мартенсит, аустенит, бейнитное превращение, легирующие элементы, непрерывное охлаждение, изотермическая закалка, микротвердость, структурная составляющая, микроструктура. 
A.N. Iurchenko, D.O. Panov, lu.N. Simonov

Perm National Research Polytechnic University, Perm, Russian Federation

\title{
CHANGE THE MICROSTRUCTURE OF SPARINGLY ALLOYED STEEL DEPENDING ON THE SPEED OF CONTINUOUS COOLING AND TEMPERATURE OF ISOTHERMAL HOLDING
}

\begin{abstract}
On the induction high-speed hardening dilatometer various modes of heat treatment of the alloy containing $0,29 \%$ of carbon and also chrome, manganese, silicon, molybdenum, vanadium are carried out. As a result of the analysis of dilatometric curves thermokinetic and isothermal diagrams of undercooled austenite decay are constructed. In article the microstructure of sparingly alloyed steel depending on the speed of continuous cooling from temperature of an austenitization and temperature of isothermal holding is analyzed. Comparison of a microstructure of alloy with values of the general microhardness when loading 100 grams on not etched microslice is given. The quantity of various microconstituents at continuous cooling and austempering is counted on dilatometric curves. Critical points of alloy which need to be known for purpose of more exact temperature of heating under quenching for obtaining the required mechanical properties are defined. It is revealed that in the process of three-hour isothermal holding bainitic transformation completely comes to an end, and the remained austenite quantity at further cooling either undergoes martensitic transformation or remains invariable. On the basis of the conducted research some assumptions that for obtaining maximum quantity of bainitic phase (or carbide-free bainite) necessary to apply isothermal holding slightly lower than temperature the beginning of martensitic transformation are made. The maximum strengthening characteristics can be received at a temperature of an isothermal holding, which is closest to temperature of the end of martensitic transformation as hardness of bainite in this case is maximum and the greatest quantity of a lath martensite is formed. Special attention is paid stability of retained austenite. After continuous cooling and austempering the quantity of austenite is insignificant that is confirmed by microstructure pictures.
\end{abstract}

Keywords: bainite, martensite, austenite, bainitic transformation, alloying elements, continuous cooling, isothermal exposure, microhardness, microconstituent, microstructure.

\section{Введение}

В настоящее время актуальной проблемой является повышение устойчивости аустенита с минимальными затратами на легирующие элементы. Устойчивость аустенита повышается, если легировать железоуглеродистый сплав, например, хромом, марганцем, никелем. Кроме того, особое значение имеет количество легирующего элемента. Например, стали системы легирования ХЗГЗМФС [1] обладают очень высокой устойчивостью аустенита, и для того, чтобы получить структуру нижнего бескарбидного бейнита (НБкБ), необходимы длительные изотермические выдержки (10-15 ч) для протекания наиболее полного бейнитного превращения.

Получение бескарбидного бейнита (БкБ) является актуальной задачей [2-7], так как давно известно, что такая структура обладает вы- 
соким комплексом механических свойств. Однако для того, чтобы получить бескарбидный бейнит, необходимо легирование стали с кремнием $[8,9]$. В данной статье показаны структуры для стали с 0,29 \% С и системой легирования Х 2 Г $2 \mathrm{C}_{1,5} \mathrm{MФ}$. Образуется однозначно бейнитная структура, но пока не подтверждено и не опровергнуто наличие карбидов в бейнитной матрице, что значительно влияет на механические характеристики сплава.

Для того чтобы выбрать режим термической обработки для исследования механических свойств сплава с $0,29 \%$ С и системой легирования Х $2 Г 2 \mathrm{C}_{1,5} \mathrm{M} Ф$, необходимо знать критические точки, а также изменение структуры при различной скорости охлаждения и температуре изотермической выдержки. Именно поэтому целью данной исследовательской работы является построение термокинетической и изотермической диаграмм распада переохлажденного аустенита для стали $29 \mathrm{X} 22_{1,5} \mathrm{M}$, а также изучение микроструктуры, микротвердости и устойчивости аустенита при непрерывном охлаждении и изотермической выдержке.

\section{Материалы и методики}

Исследовали железоуглеродистый сплав со следующим химическим составом (мас. \%): $\mathrm{C}-0,29 ; \mathrm{Cr}-2,2 ; \mathrm{Mn}-1,7 ; \mathrm{Si}-1,53$; $\mathrm{Mo}-$ 0,36; $\mathrm{Ni}-0,32 ; \mathrm{S}-0,011 ; \mathrm{P}-0,015$. Состояние поставки сплава: горячекованые прутки диаметром 23 мм с твердостью 53-55 HRC.

Экспериментальные режимы термической обработки проводили на высокоскоростном индукционном закалочном дилатометре LINSEIS L78 R.I.T.A. на образцах длиной 10 мм и диаметром 3 мм в среде чистого гелия. Образцы закрепляли в кварцевые держатели. Для контроля температуры использовали термопару К-типа.

При термокинетических режимах скорость нагрева $\left(v_{\text {нагр }}=\right.$ $\left.=1,5^{\circ} \mathrm{C} / \mathrm{c}\right)$, температура нагрева $\left(T_{\text {нагр }}=1000{ }^{\circ} \mathrm{C}\right)$, время выдержки $\left(\tau_{\text {выд }}=15\right.$ мин $)$ оставались неизменными, а скорость охлаждения была различной: $100 ; 1,5 ; 0,3 ; 0,1 ; 0,05^{\circ} \mathrm{C} / \mathrm{c}$.

При изотермической закалке скорость нагрева $\left(v_{\text {нагр }}=1,5{ }^{\circ} \mathrm{C} / \mathrm{c}\right)$ и скорость охлаждения $\left(v_{\text {охл }}=1,5^{\circ} \mathrm{C} / \mathrm{c}\right)$, температура нагрева $\left(T_{\text {нагр }}=\right.$ $\left.=1000{ }^{\circ} \mathrm{C}\right)$, время выдержки ( $\tau_{\text {выд }}=15$ мин), время выдержки при температуре изотермы ( $\tau_{\text {изо }}=3$ ч) оставались неизменными, а температуру изо-

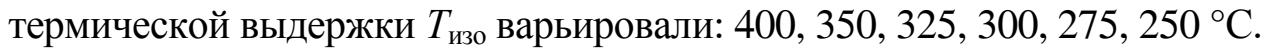


Оценку твердости исследуемых материалов проводили на микротвердомере ПМТ-3 при нагрузке 100 г $\left(\mathrm{HV}_{0,1}\right)$. Значение твердости определяли как среднее арифметическое по результатам 25-30 замеров.

Микроструктуру исследовали на микрошлифах, приготовленных на поперечном сечении дилатометрических образцов. Микрошлифы изготавливали путем запрессовки образцов в автоматическом монтажном пресcе Struers CitoPress-10 и дальнейшего шлифования на шлифовально-полировальном станке Struers Tegramin-30. Для травления использовали 4\%-ный раствор азотной кислоты в этиловом спирте. Травленые микрошлифы исследовали на световом инвертированном микроскопе Olympus GX-51 при увеличении до ×1000 включительно.

\section{Результаты и их обсуждение}

По результатам проведенных режимов термокинетической обработки определены критические точки $A_{C_{1}}=704{ }^{\circ} \mathrm{C}$ и $A_{C_{3}}=870{ }^{\circ} \mathrm{C}$, построена термокинетическая диаграмма распада переохлажденного аустенита (рис. 1). В процессе самых быстрых скоростей охлаждения, выше $1,5^{\circ} \mathrm{C} / \mathrm{c}$, аустенит претерпевает преимущественно мартенситное превращение. Микротвердость составляет $\mathrm{HV}_{0,1}=(582 \pm 14) \mathrm{\kappa} / \mathrm{MM}^{2}$. Микроструктура представлена на рис. 2, $a$. Морфология мартенсита является реечной.

При скорости охлаждения $1,5^{\circ} \mathrm{C} / \mathrm{c}$ появляются первые порции нижнего бейнита, но, как видно из рис. 2,6 , микроструктура имеет все еще преимущественно мартенситный характер.

При дальнейшем понижении скорости охлаждения вплоть до самой медленной $\left(0,05^{\circ} \mathrm{C} / \mathrm{c}\right)$ бейнитная составляющая проявляется в бо́льшей степени. Особенно это наглядно представлено на изображениях микроструктуры на рис. 2, в, г. Видно, как на фоне мартенситной матрицы происходит выделение бейнитных темных игл. Замечено, что по мере уменьшения скорости охлаждения бейнитная область начинает расширяться, а мартенситная сжиматься. Как видно из диаграммы, температура начала мартенситного превращения $\mathrm{M}_{\mathrm{H}}$ снижается, а температура конца мартенситного превращения $\mathrm{M}_{\mathrm{\kappa}}$ немного повышается.

При самой медленной скорости охлаждения не замечено мартенситного превращения, а наряду с незначительным выделением нижнего бейнита происходит образование перистой морфологии бейнита 
(или верхнего бейнита) (рис. 2, d). Общая микротвердость резко снижается до $\mathrm{HV}_{0,1}=(460 \pm 9) \mathrm{\kappa} / \mathrm{Mм}^{2}$.

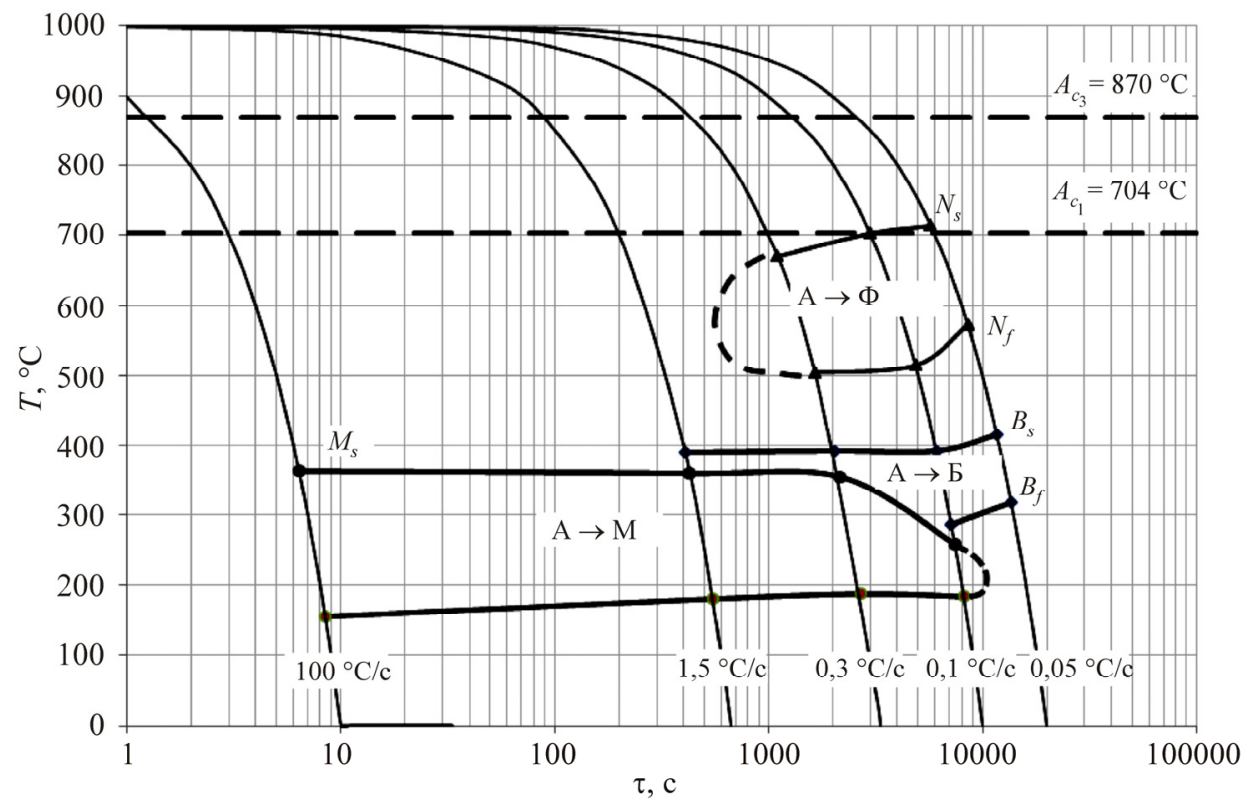

Рис. 1. Термокинетическая диаграмма распада переохлажденного аустенита исследуемого сплава

Кроме бейнитной и мартенситной областей выделяется область нормального превращения, где происходит превращение из аустенита в феррит, но по металлографическому анализу заметны только незначительные поля или следы избыточного феррита. Такое количество избыточного феррита может не влиять на изменение механических свойств, но появление такой фазы нежелательно. Кроме того, выявление такой области говорит о том, что аустенит является метастабильным при медленном охлаждении в области нормальных температур.

При непрерывном охлаждении с любой скоростью в структуре присутствует доля остаточного аустенита. Желательно, чтобы объем остаточного аустенита после всех превращений был существенным для внесения положительного эффекта в надежность материала, но в данном случае аустенит является недостаточно стабильным и нужно проводить дополнительные исследования для обнаружения различных модификаций остаточного аустенита. 

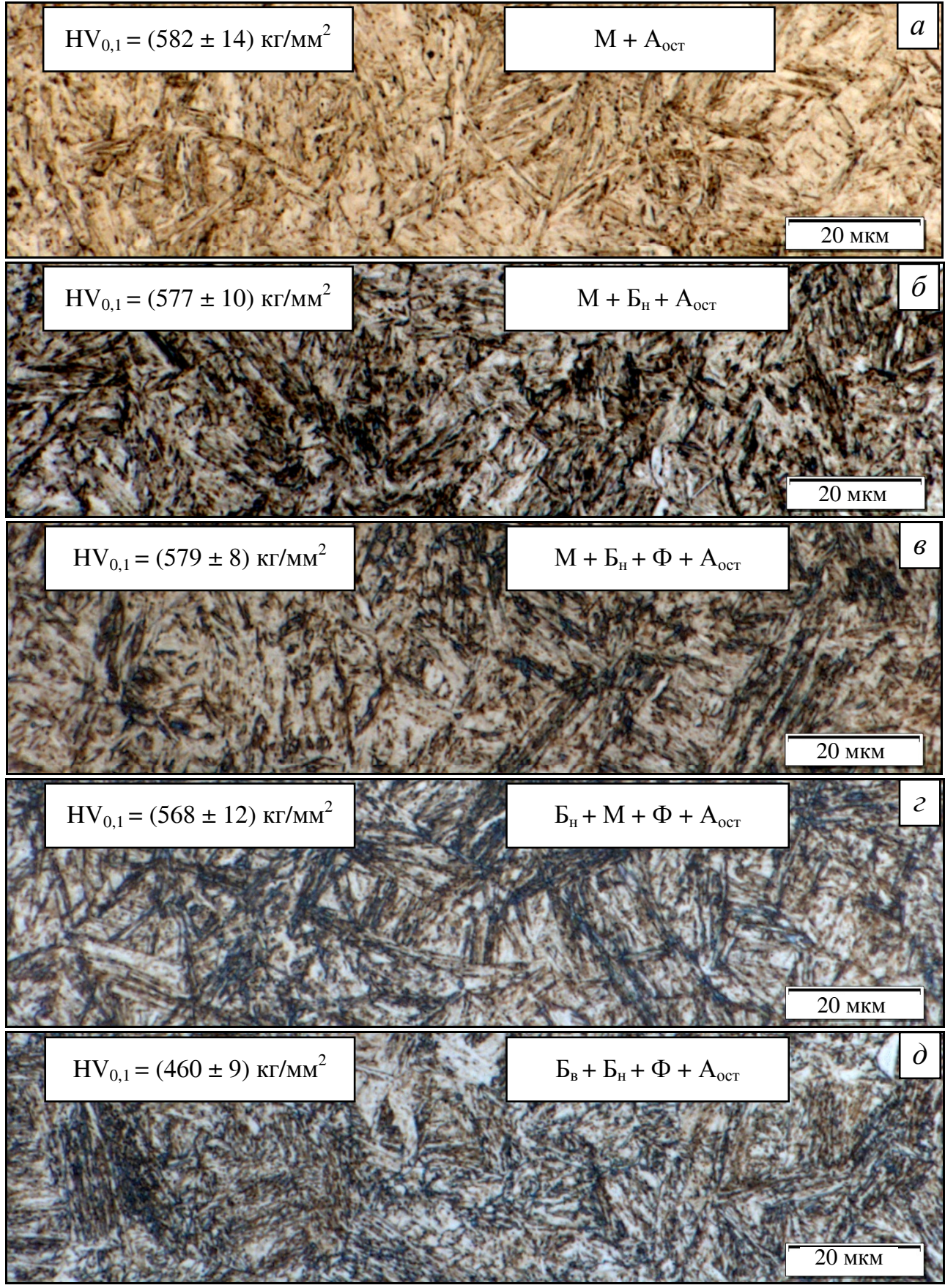

Рис. 2. Микроструктура стали при различной скорости непрерывного охлаждения: $a-100{ }^{\circ} \mathrm{C} / \mathrm{c} ; \sigma-1,5{ }^{\circ} \mathrm{C} / \mathrm{c} ; \beta-0,3{ }^{\circ} \mathrm{C} / \mathrm{c} ; z-0,1{ }^{\circ} \mathrm{C} / \mathrm{c} ; \partial-0,05^{\circ} \mathrm{C} / \mathrm{c}(\times 1000)$ 
На рис. 3 представлена изотермическая диаграмма распада переохлажденного аустенита. На диаграмме нанесены количественные показатели мартенсита (в процентах), который образовался до изотермической выдержки, и бейнита, который превращается из аустенита в процессе изотермической выдержки.

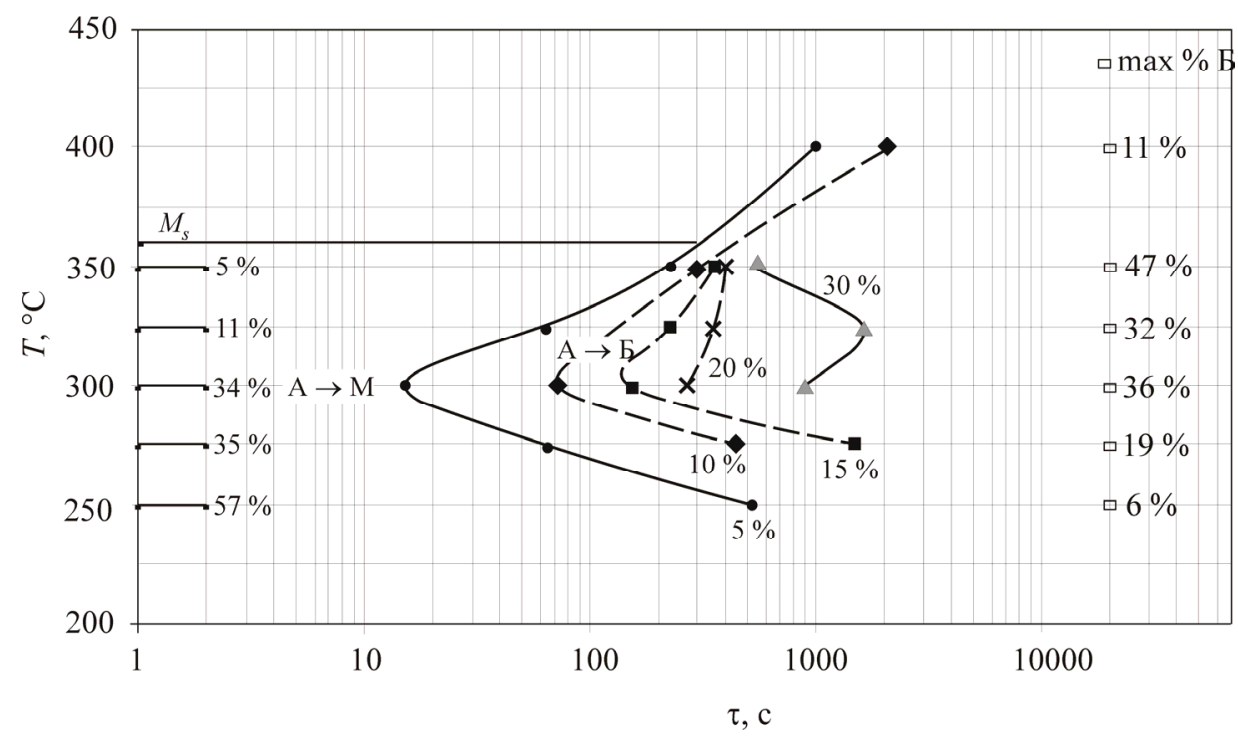

Рис. 3. Изотермическая диаграмма распада переохлажденного аустенита исследуемого сплава

При $T_{\text {изо }}=400{ }^{\circ} \mathrm{C}$, что выше $\mathrm{M}_{\mathrm{H}}$, образуется некоторое количество смеси верхнего и нижнего бейнита. Основную долю микроструктуры исследуемой стали занимает мартенсит охлаждения, который образу-

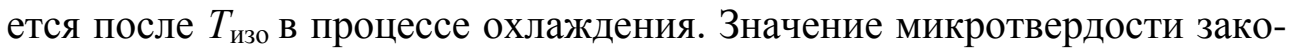
номерно соответствует твердости мартенсита. Микроструктура изображена на рис. $4, a$. Необходимо отметить, что такая структура однозначно нежелательна, так как есть верхний бейнит и очень большое количество мартенсита охлаждения, что будет отрицательно сказываться на ударных характеристиках.

В процессе проведения остальных пяти режимов обработки, ко-

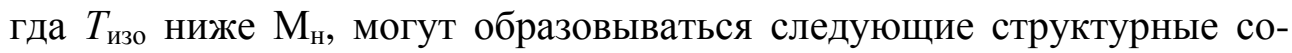
ставляющие: атермический [11] и изотермический мартенсит, нижний бейнит [12-14], нижний бескарбидный бейнит, мартенсит охлаждения. Качественное и количественное разделение такого типа структурных 
составляющих - сложная задача, поэтому является темой отдельного исследования. В данной работе представлены только некоторые количественные характеристики.

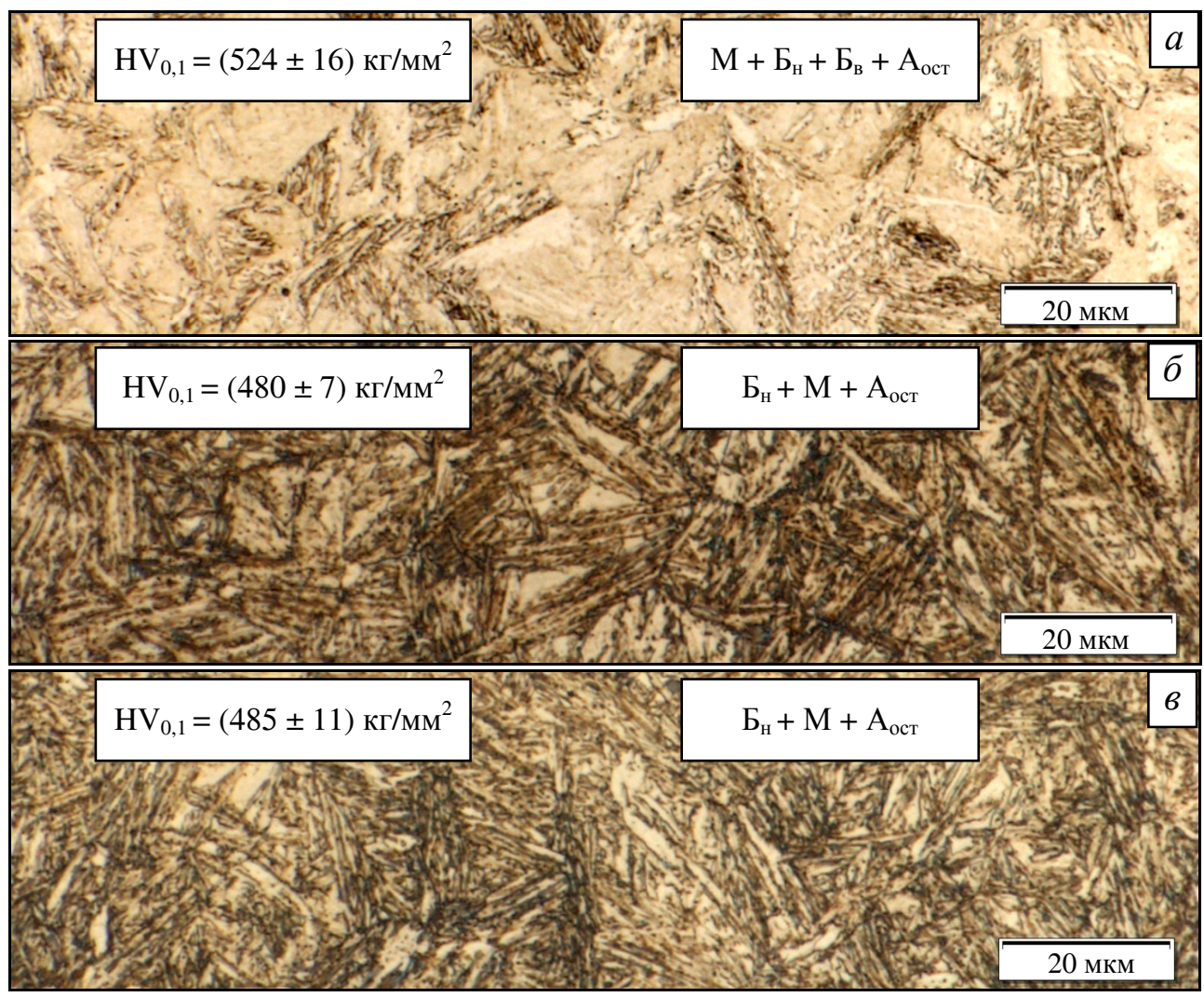

Рис. 4. Микроструктура стали после изотермической закалки при $T_{\text {изо }}$ :

$$
a-400{ }^{\circ} \mathrm{C} ; \sigma-350{ }^{\circ} \mathrm{C} ; в-325^{\circ} \mathrm{C}(\times 1000)
$$

При $T_{\text {изо }}=350{ }^{\circ} \mathrm{C}$ формируется микроструктура нижнего крупноигольчатого с зубчатыми границами бейнита, а также незначительное количество атермического мартенсита (рис. 4, б). Всё остальное, предполагается, мартенсит охлаждения и остаточный аустенит. При этом режиме образуется максимальное количество бейнита.

При последующих изотермических выдержках происходит увеличение доли атермического мартенсита до $57 \%$, а объем бейнитной фазы снижается до 6 \%. Предполагается, что в процессе изотермической выдержки наряду с бейнитным превращением протекает изотер-

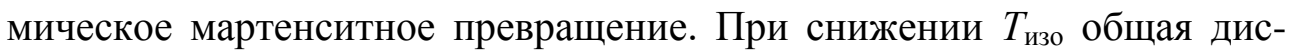


персность структуры увеличивается, поэтому точное разграничение мартенсита и бейнита по микроструктуре невозможно (см. рис. 4; 5). Бейнитное превращение в процессе изотермической выдержки заканчивается за 3 ч, поэтому с точки зрения технологичности процесса сплав с химическим составом (мас. \%): $\mathrm{C}-0,29 ; \mathrm{Cr}-2,2 ; \mathrm{Mn}-1,7 ; \mathrm{Si}-$ 1,53; Мо - 0,36; Ni - 0,32; S - 0,011; P - 0,015\% - является целесообразным для использования, но в связи с неустойчивостью аустенита при последующем охлаждении может быть ограниченно применим.

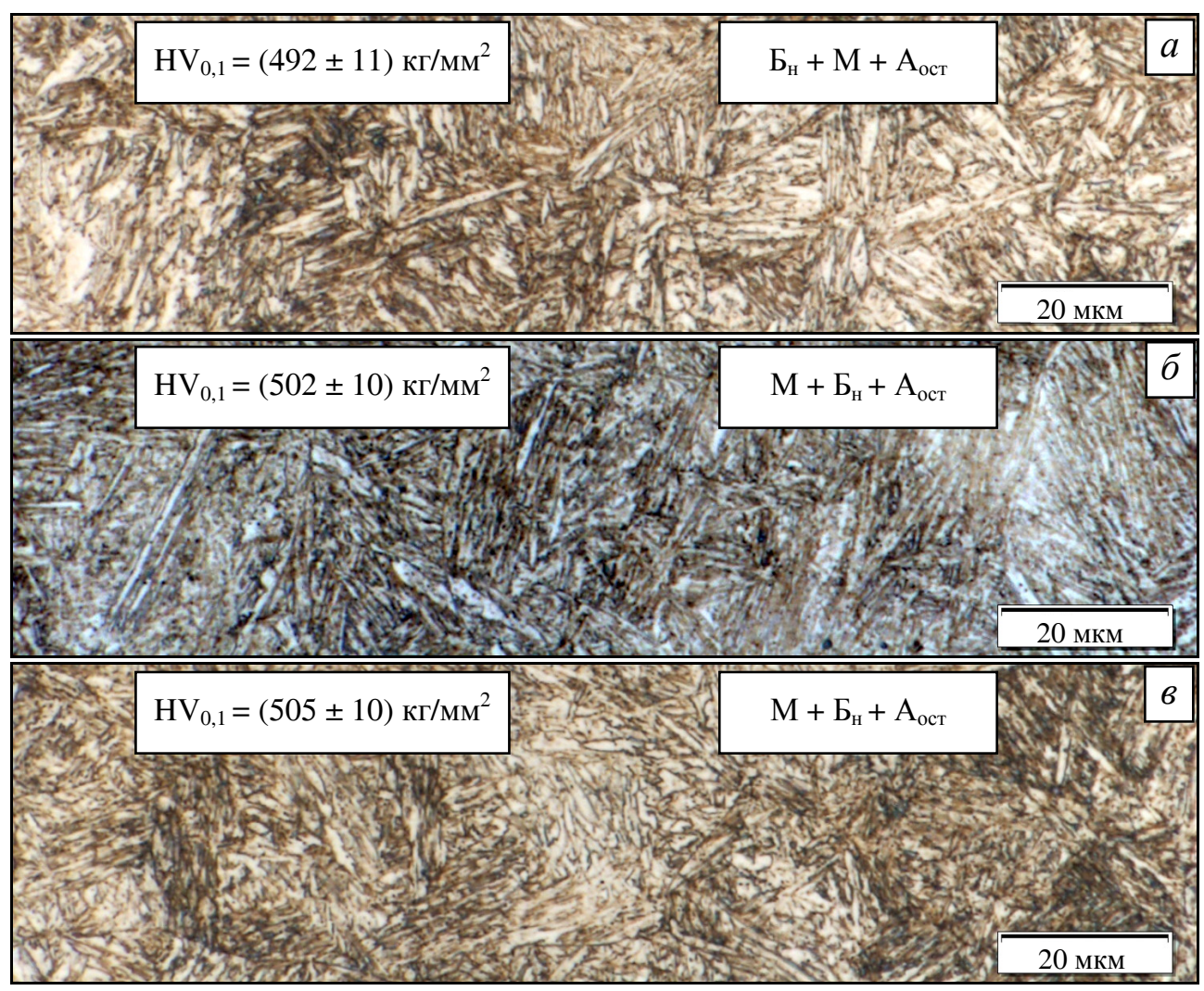

Рис. 5. Микроструктура стали после изотермической закалки при $T_{\text {изо }}$ :

$$
a-300{ }^{\circ} \mathrm{C} ; \sigma-275^{\circ} \mathrm{C} ; в-250{ }^{\circ} \mathrm{C}(\times 1000)
$$

\section{Заключение}

Для получения максимальных прочностных характеристик и повышенных показателей надежности с бейнитной структурой рекомендуется $T_{\text {изо }}=250 \ldots 300{ }^{\circ} \mathrm{C}$, так как при таких температурах образуется 
большое количество атермического пакетного мартенсита, а комплекс механических свойств нижнего бейнита должен быть максимальным при самой низкой $T_{\text {изо }}$ Предполагается, что бейнит является бескарбидным, так как в стали присутствует достаточное количество кремния.

Аустенит является метастабильным, так как в области температур нормального превращения возможно образование избыточного феррита, что отрицательно влияет на механические свойства.

При всех термокинетических и изотермических режимах обработки образуется смешанная структура, состоящая из мартенсита и бейнита. Исключением является режим с самым медленным непрерывным охлаждением $\left(v_{\text {охл }}=0,05{ }^{\circ} \mathrm{C} / \mathrm{c}\right)$. При этом образуется только верхний бейнит со следами избыточного феррита.

При скоростях охлаждения $100 ; 1,5 ; 0,3 ; 0,1$ $\mathrm{C} / \mathrm{c}$ заметно преобладание мартенситной матрицы, на фоне которой располагаются бейнитные области, что согласуется со значениями микротвердости.

Общая дисперсность структуры увеличивается при повышении скорости непрерывного охлаждения до $100{ }^{\circ} \mathrm{C} / \mathrm{c}$ и понижении $T_{\text {изо }}$

\section{Список литературы}

1. Получение структуры нижнего бескарбидного бейнита в результате изотермической обработки сталей типа ХЗГЗМФС и ХНЗМФС / Ю.Н. Симонов, М.Ю. Симонов, Д.О. Панов, В.П. Вылежнев, А.Ю. Калетин // МиТОМ. - 2016. № 2. - C. 4-12.

2. Xiaoxu Zhang, Guang Xu, Xiang Wang, David Embury, Olivier Bouaziz, Gary R. Purdy, Hatem S. Zurob. Mechanical behavior of carbide-free medium carbon bainitic steels // Metallurgical and Materials Transactions. - 2014. - № 3. - P. 1352-1361.

3. Калетин А.Ю., Калетина Ю.В. Повышение вязкости конструкционных сталей при образовании бескарбидного бейнита // Вестник Пермского национального исследовательского политехнического университета. Машиностроение, материаловедение. - 2014. - Т. 16, № 4. - С. 22-30.

4. Принципы конструирования химического состава сталей для получения структуры нижнего бескарбидного бейнита при замедленном охлаждении / Ю.Н. Симонов, Д.О. Панов, М.Ю. Симонов, В.П. Вылежнев, А.С. Иванов // МиТОМ. - 2015. № 7. - С. 20-28.

5. Симонов Ю.Н., Георгиев М.Н. Принципы конструирования химического состава сталей для получения в них структуры нижнего бескарбидного бейнита при замедленном охлаждении // Инновационные технологии в машиностроении и материаловедении: сб. тез. 2-й науч.-практ. конф. с междунар. участием. - Пермь: Изд-во Перм. нац. исслед. политехн. ун-та, 2014. - С. 184-188. 
6. Калетин А.Ю., Рыжков А.Г., Калетина Ю.В. Повышение ударной вязкости конструкционных сталей при образовании бескарбидного бейнита // ФММ. - 2015. T. 116, № 1. - С. 114-120.

7. Способы достижения нижнего бескарбидного бейнита для специальных видов сталей / С.В. Лекомцев, Д.О. Панов, М.Ю. Симонов, И.Н. Шардаков // Науч.техн. вестник Поволжья. - 2014. - № 6. - С. 204-209.

8. Леонтьев П.А., Иванова А.С., Симонов Ю.Н. Исследование фазовых превращений и структуры кремнистых сталей с различным содержанием углерода при непрерывном охлаждении // Вестник Пермского национального исследовательского политехнического университета. Машиностроение, материаловедение. - 2013. T. 15, № 4. - С. 33-39.

9. Калетин А.Ю., Калетина Ю.В. Эволюция структуры и свойств кремнистых сталей при фазовом переходе аустенит-бейнит // ФТТ. - 2015. - Т. 57, вып. 1. С. 56-62.

10. Исследование кинетики образования нижнего бейнита в структуре высокоуглеродистой низколегированной стали / А.Д. Коваль, М.Н. Брыков, А.Е. Капустян, Д.Н. Тимофеенко // Нові матеріали і технології в металургії та машинобудуванні. - 2011. - № 2. - C. 17-21.

11. Navarro-Lopez A., Sietsma J., Santofimia M.J. Effect of prior athermal martensite on the isothermal tranformation kinetics below $M_{s}$ in a low-C high-Si steel // Metallurgical and materials transactions. - 2015. - № 12. - P. 1028-1039.

12. Bhadeshia H.K.D.H. Bainite in steels. - 2nd ed. / Institute of Materials. - London, 2001. $-460 \mathrm{c}$.

13. Caballero F.G., Bhadeshia H.K.D.H. Very strong bainite // Current Opinion in Solid State and Materials Science: DK 8. - 2004. - P. 251-257.

14. Effect of austempering route on microstructural characterization of nanobainitic steel / Huifang Lan, Linxiu Du, Na Zhou, Xianghua Liu // Acta Metall. Sin. (Engl. Lett.). 2014. - № 27(1). - P. 19-26.

\section{References}

1. Simonov Iu.N., Simonov M.Iu., Panov D.O., Vylezhnev V.P., Kaletin A.Iu. Poluchenie struktury nizhnego beskarbidnogo beinita $\mathrm{v}$ rezul'tate izotermicheskoi obrabotki stalei tipa Kh3G3MFS i KhN3MFS [Receiving structure of the lower beskarbidny beynit as a result of isothermal processing staly the H3G3MFS and HN3MFS type]. Metal Science and Heat Treatment, 2016, no. 2, pp. 4-12.

2. Xiaoxu Zhang, Guang Xu, Xiang Wang, David Embury, Olivier Bouaziz, Gary R. Purdy, Hatem S. Zurob. Mechanical behavior of carbide-free medium carbon bainitic steels. Metallurgical and Materials Transactions, 2014, no. 3, pp. 1352-1361.

3. Kaletin A.Iu., Kaletina Iu.V. Povyshenie viazkosti kon-struktsionnykh stalei pri obrazovanii beskarbidnogo beinita [Increase in viscosity constructional staly at formation of a beskarbidny beynit]. Vestnik Permskogo natsional'nogo issledovatel'skogo politekhnicheskogo universiteta. Mashinostroenie, materialovedenie, 2014, vol. 16, no. 4, pp. 22-30. 
4. Simonov Iu.N., Panov D.O., Simonov M.Iu., Vylezhnev V.P., Ivanov A.S. Printsipy konstruirovaniia khimicheskogo sostava stalei dlia polucheniia struktury nizhnego beskarbidnogo beinita pri zamedlen-nom okhlazhdenii [The principles of designing of the chemical composition of structure of the lower beskarbidny beynit, staly for receiving, at the slowed-down cooling]. Metal Science and Heat Treatment, 2015, no.7, pp. 20-28.

5. Simonov Iu.N., Georgiev M.N. Printsipy konstruirovaniia khimicheskogo sostava stalei dlia polucheniia $\mathrm{v}$ nikh struktury nizhnego beskarbidnogo beinita pri zamedlennom okhlazhdenii [The principles of designing of the chemical composition of structure, staly for receiving, in them the lower beskarbidny beynit at the slowed-down cooling]. Innovatsionnye tekhnologii $v$ mashinostroenii $i$ materialovedenii: sbornik tezisov 2-i nauchno-prakticheskoi konferentsii s mezhdunarodnym uchastiem, Perm', Izdatel'stvo Permskogo natsional'nogo issledovatel'skogo politekhnicheskogo universiteta, 2014, pp. 184-188.

6. Kaletin A.Iu., Ryzhkov A.G., Kaletina Iu.V. Povyshenie udarnoi viazkosti konstruktsionnykh stalei pri obrazovanii beskarbidnogo beinita [Increase in impact strength constructional staly at formation of a beskarbidny beynit]. The Physics of Metals and Metallography, 2015, vol. 116, no. 1, pp. 114-120.

7. Lekomtsev S.V., Panov D.O., Simonov M.Iu., Shardakov I.N. Sposoby dostizheniia nizhnego beskarbidnogo beinita dlia spetsial'nykh vidov stalei / [Ways of achievement of the lower beskarbidny beynit for special types of staly]. Nauchno-tekhnicheskii vestnik Povolzh'ia, 2014, no. 6, pp. 204-209.

8. Leont'ev P.A., Ivanova A.S., Simonov Iu.N. Issledovanie fazovykh prevrashchenii i struktury kremnistykh stalei s razlichnym soderzhaniem ugleroda pri nepreryvnom okhlazhdenii [Research of phase transformations and structure siliceous staly with various content of carbon at continuous cooling]. Vestnik Permskogo natsional'nogo issledovatel'skogo politekhnicheskogo universiteta. Mashinostroenie, materialovedenie, 2013, vol. 15, no. 4, pp. 33-39.

9. Kaletin A.Iu., Kaletina Iu.V. Evoliutsiia struktury i svoistv kremnistykh stalei pri fazovom perekhode austenitbeinit [Evolution of structure and properties siliceous staly upon phase transition austenite-beynit]. Fizika tverdovogo tela, 2015, vol. 57, iss. 1, pp. 56-62.

10. Koval A.D., Brykov M.N., Kapustian A.E., Timofeenko D.N. Issledovanie kinetiki obrazovaniia nizhnego beinita $\mathrm{v}$ strukture vysokouglerodistoi nizkolegirovannoi stali [A research of kinetics of formation of the lower beynit in structure of the high carbon lowalloyed steel]. Novi materiali i tekhnologï v metalurgï ta mashinobuduvanni, 2011, no. 2, pp. 17-21.

11. Navarro-Lopez A., Sietsma J., Santofimia M.J. Effect of prior athermal martensite on the isothermal tranformation kinetics below Ms in a low-C high-Si steel. Metallurgical and materials transactions, 2015, no. 12, pp. 1028-1039.

12. Bhadeshia H.K.D.H. Bainite in steels. 2nd ed. Institute of Materials, London, 2001, 460 p.

13. Caballero F.G., Bhadeshia H.K.D.H. Very strong bainite. Current Opinion in Solid State and Materials Science: DK 8, 2004, pp. 251-257. 
14. Huifang Lan, Linxiu Du, Na Zhou, Xianghua Liu. Effect of austempering route on microstructural characterization of nanobainitic steel. Acta Metall. Sin. (Engl. Lett.), 2014, no. 27(1), pp. 19-26.

Получено 26.01.2016

\title{
Об авторах
}

Юрченко Александр Николаевич (Пермь, Россия) - аспирант кафедры металловедения, термической и лазерной обработки металлов Пермского национального исследовательского политехнического университета; e-mail: sanyaurchenko4@ gmail.ru.

Панов Дмитрий Олегович (Пермь, Россия) - кандидат технических наук, доцент кафедры металловедения, термической и лазерной обработки металлов Пермского национального исследовательского политехнического университета; e-mail: dimmak-panov@mail.ru.

Симонов Юрий Николаевич (Пермь, Россия) - доктор технических наук, профессор, заведующий кафедрой металловедения, термической и лазерной обработки металлов Пермского национального исследовательского политехнического университета; e-mail: mto@pstu.ru, simonov@pstu.ru.

\begin{abstract}
About the authors
Aleksandr N. Iurchenko (Perm, Russian Federation) - Postgraduate Student, Department of Metal Science, Laser and Heat Treatment of Metals, Perm National Research Polytechnic University; e-mail: sanyaurchenko4@gmail.ru.

Dmitrii O. Panov (Perm, Russian Federation) - Ph. D. in Technical Sciences, Associate Professor, Department of Metal Science, Laser and Heat Treatment of Metals, Perm National Research Polytechnic University; e-mail: dimmak-panov@mail.ru.

Iuri N. Simonov (Perm, Russian Federation) - Doctor of Technical Sciences, Professor, Department of Metal Science, Laser and Heat Treatment of Metals, Perm National Research Polytechnic University; e-mail: mto@pstu.ru, simonov@pstu.ru.
\end{abstract}

